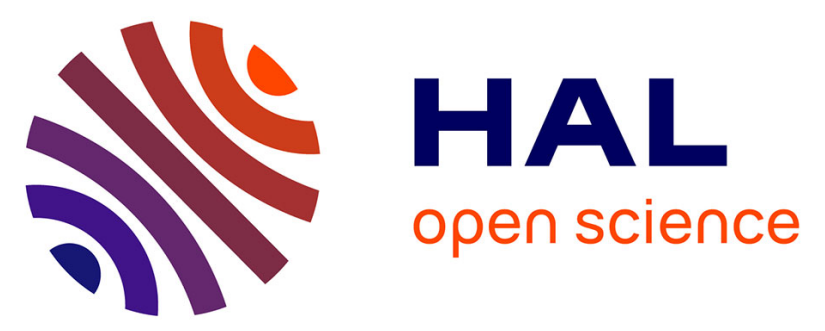

\title{
Alterations in Cortical Morphology after Neonatal Stroke: Compensation in the Contralesional Hemisphere?
}

Mariam Al Harrach, François Rousseau, Samuel Groeschel, Xiaoyu Wang, Lucie Hertz-pannier, Stéphane Chabrier, Amine Bohi, Julien Lefèvre, Mickaël Dinomais

\section{To cite this version:}

Mariam Al Harrach, François Rousseau, Samuel Groeschel, Xiaoyu Wang, Lucie Hertz-pannier, et al.. Alterations in Cortical Morphology after Neonatal Stroke: Compensation in the Contralesional Hemisphere?. Developmental Neurobiology, 2019, 79 (4), pp.303-316. 10.1002/dneu.22679 . hal02285917

\section{HAL Id: hal-02285917 https://imt-atlantique.hal.science/hal-02285917}

Submitted on 16 Sep 2019

HAL is a multi-disciplinary open access archive for the deposit and dissemination of scientific research documents, whether they are published or not. The documents may come from teaching and research institutions in France or abroad, or from public or private research centers.
L'archive ouverte pluridisciplinaire HAL, est destinée au dépôt et à la diffusion de documents scientifiques de niveau recherche, publiés ou non, émanant des établissements d'enseignement et de recherche français ou étrangers, des laboratoires publics ou privés. 


\title{
Alterations in Cortical Morphology after Neonatal Stroke: Contralesional hemisphere Compensation?
}

\author{
(Neonatal stroke outcome on cortical morphology)
}

Mariam Al Harrach', François Rousseau ${ }^{2}$, Samuel Gröschel ${ }^{3}$, Xiaoyu Wang², Lucie Hertz-pannier ${ }^{4}$, Stéphane Chabrier ${ }^{5,6}$, Amine Bohi ${ }^{7}$, Julien Lefevre ${ }^{7}$ and Mickael Dinomais ${ }^{1,8}$

1 Université d'Angers, Laboratoire Angevin de Recherche en Ingénierie des Systèmes (LARIS)

EA7315, 49000 Angers, France

2 IMT Atlantique, INSERM U1101 LaTIM, UBL, 29200 Brest, France

3 Experimental Paediatric Neuroimaging, Department of Child Neurology, University Hospital

Tübingen, Germany

4 UNIACT, Neurospin, I2BM, DSV, CEA-Saclay, and Inserm U1129 Paris ; Université Paris

Descartes, Sorbonne Paris Cité ; CEA, Gif sur Yvette, F-91191, France

5 INSERM, UMR1059 Sainbiose, Univ Saint-Étienne, Univ Lyon, F-42023 Saint-Étienne, France

6 CHU Saint-Étienne, French Centre for Paediatric Stroke, Paediatric Physical and Rehabilitation

Medicine Department, INSERM, CIC 1408, F-42055 Saint-Étienne, France

7 Institut de Neurosciences de la Timone UMR 7289, Aix Marseille Université, CNRS, 13385

Marseille, France.

8 CHU Angers, Département de Médecine Physique et de Réadaptions and LUNAM, Angers, France.

Correspondence to: Mariam Al Harrach

Laboratoire Angevin de Recherche en Ingénierie des Systèmes

Université d'Angers

62 avenue Notre Dame du Lac, 49000 Angers, France

Email: mariam.alharrach@univ-angers.fr 


\begin{abstract}
Although neonatal arterial ischemic Stroke is now well-studied, its complex consequences on long-term cortical brain development has not yet been solved. In order to understand the brain development after focal early brain lesion, brain morphometry needs to be evaluated using structural parameters. In this work, our aim was to study and analyse the changes in the morphometry of ipsilesional and contralesional hemispheres of seven-year-old children following neonatal stroke. Therefore, we used surface-based morphometry in order to examine the cortical thickness, surface area, cortical volume and local gyrification index in two groups of children that suffered from neonatal stroke in the left $(n=19)$ and right hemispheres $(n=15)$ and a group of healthy controls $(n=30)$. Reduced cortical thickness, surface area and cortical volumes were observed in the ipsilesional hemispheres for both groups in comparison with controls. For the left lesioned group, an increase in the gyrification of the contralesional hemisphere underlined by an increase in surface area and cortical volume was observed primarily in the occipital region. As for the right lesioned group, higher gyrification was detected in two different clusters also in the contralesional hemisphere. However, these alterations in the gyrifications were not accompanied by a significant change in the cortical thickness, surface area or cortical volume in the occipital lobe. This is the first time that increase of the structural parameters is detected in the "healthy" hemisphere after unilateral neonatal stroke suggesting a compensatory phenomenon. Moreover, findings presented in this work suggest that lesion lateralization might have an influence on brain development and maturation.
\end{abstract}

Keywords: neonatal arterial ischemic stroke, cortical thickness, local gyrification index, surface area, FreeSurfer.

Abbreviations: NAIS = Neonatal Arterial Ischemic Stroke, LGI=Local Gyrification Index, $\mathrm{HC}=$ Healthy Controls, VBM $=$ Voxel-Based Morphometry, VLSM = Voxel-Based LesionSymptom Mapping, DTI $=$ Diffusion Tensor Imaging, MCA $=$ Middle Cerebral Artery, LLP= Left lesioned Patients, LH= Left Hemisphere, RLP= Right Lesioned Children, RH= Right Hemisphere, TIV= Total Intracranial Volume 


\section{Introduction}

Perinatal ischemic stroke, as defined as a "heterogeneous conditions with a focal cerebral arterial or venous occlusion, occurring between 20 weeks of foetal life through 28 th postnatal day" (Raju et al., 2007), appears more and more as an umbrella term which encompasses a variety of clinical entities. Neonatal Arterial Ischemic Stroke (NAIS) represents a unique model to study the impact of an early stroke on brain development, as the lesion and its timing are well circumscribed (Kirton, 2013; Grunt et al. 2015). Affected children will sustain cerebrovascular arterial insults occurring between birth and the $28^{\text {th }}$ day of life (Stephan-Otto et al. 2017). According to Diffusion-weighted imaging, critical focal brain infarction is mostly located in a large artery; more precisely the left middle cerebral artery (Raju et al. 2007; Kirton \&deVeber, 2013).

NAIS birth-prevalence in term or near-term new-borns varies from 6 to 17/100,000 live births (Darmency-Stamboul, Cordier, \& Chabrier, 2017). Studies looking at NAIS show that approximately $60 \%$ of children exhibit some mild neurodevelopment disabilities at school-age (Kirton \& deVeber, 2013). However, it has risen as a principal cause of perinatal brain injury, hemiparetic cerebral palsy, and lasting disability (Kirton et al. 2011). Furthermore, NAIS may trigger structural changes in both grey and white matter regions internal and remote to the infarct site (Dinomais et al., 2015).

Neuroimaging studies on brain morphometry after early brain lesion provide interesting insights into the capacity, but also the limits, of brain (re)organization in the development course (Staudt, 2010a, 2010b). Research shows the potential of human brain to compensate for pre and perinatal focal brain lesions (Staudt, 2010a). This compensation is established through the contralesional hemisphere, where it will conduct motor functions in the paretic extremities (Staudt, 2010a, 2010b; Dinomais et al. 2015; Zewdie et al., 2017). Moreover, in addition to motor system, different types of functional (re)organization were described in the literature including somatosensory and language systems (Staudt, 2010a, 2010b). On these accounts, studying the brain morphology after several years could help to better apprehend the long-term structural effect of NAIS.

Different approaches are adopted in the literature in order to study and explore the brain structural development. Most of these studies used classical approaches (Voxel-Based Morphometry (VBM), Voxel-Based Lesion-Symptom Mapping (VLSM) or Diffusion Tensor Imaging (DTI)) which do not allow an in-depth examination of the cortex (Van Der Aa et al., 2013; Dinomais et al., 2015). This research field has undergone recent methodological 
advances where different approaches have been extensively used as tools to measure specific morphometric variables of the cortex including cortical thickness, surface area, cortical volume, complexity and gyrification (Kelly et al., 2013; Gerrits et al., 2016). These metrics have proven to be independently powerful as tools to evaluate differences or abnormalities in the brain structure in certain brain disorder cases like Autism (Libero et al., 2014), Parkinson's disease (Gerrits et al., 2016), schizophrenia (Schultz et al., 2013) and bipolar disorder (Rimol et al., 2012) or even in psychologically affected children (maltreatment, abuse and neglect) (Kelly et al., 2013). However, to date, no information on the cortical shaping are available at long term after NAIS.

The aim of this study was to explore the impact of unilateral NAIS on the development of the cortex at age seven, using new approaches. This was done using cortical thickness, surface area, cortical volume and local gyrification for patients with lesions in the left and right hemisphere separately. The lesion lateralization was considered by separating the patients into two groups based on the side of the unilateral lesion. This was motivated by the brain asymmetry studies as well as the importance of laterality in different brain functions such as language (Staudt, 2010a). Accordingly, we recruited three groups of children: a control group of healthy children, a Left Lesioned Patients (LLP) with unilateral NAIS in the Left Hemisphere (LH) and a Right lesioned Patients (RLP) with unilateral NAIS at the Right Hemisphere (RH). Finally, to investigate the effects of NAIS on the previously mentioned parameters, we were also keen to explore the impact of the lesion lateralization on these brain biomarkers especially for the contralesional hemisphere.

\section{Materials and methods}

\section{Participants}

Patients belonged to the previously described AVCnn cohort (Accident Vasculaire Cerebral du nouveau-ne, that is, neonatal stroke-PHRC regional n80308052 and PHRC interregional n81008026 -eudract number 2010-A00329-30) (Dinomais et al., 2015). In short, 100 term newborns with an arterial infarct, confirmed by brain imaging (CT and/or MRI), who were symptomatic in the neonatal period (thus matching the 2007 definition of NAIS (Raju et al., 2007)) were consecutively enrolled between November 2003 and October 2006 from 39 neonatology and neuropediatric units distributed throughout mainland France. At the age of 7 years, a clinical follow-up visit was organized, and an MRI investigation was proposed to the 80 children who took part in the clinical evaluation. Of the 52 children who participated in the 
MRI study, 38 had unilateral MRI lesions in the MCA territory. They constituted the patient population of this study (eudract number 2010-A00976-33). Patients with lesion in the left (LLP) and right hemisphere (RLP) were processed separately without masking out the brain lesions or projecting the lesioned hemisphere onto the left one as previously done (Dinomais et al., 2015). By keeping the original orientation of the brain without flipping the image in the left-right direction we eliminate the ambiguity and inaccuracy that arises from the asymmetry of the brain (Kong et al., 2018). However, after further examination we only kept 34 patients divided between LLP and RLP. Four patients were eliminated due to poor segmentation by reason of the position of the corresponding brain lesions (for more details please refer to section MRI Acquisition and processing). Along with the LLP and RLP patients we recruited 30 Healthy Controls (HC). These controls were chosen to be of similar age and gender distribution as the patients. General profile and characteristics of the participants are presented in Table 1. Informed written consent respecting the declaration of Helsinki were obtained from participants/parents as well as approval from the ethical committee of the university hospital of Angers, France. Handedness was assessed according to the Edinburgh inventory (Oldfield, 1971).

\section{MRI Acquisition and Processing}

Images were acquired on a 3.0 Tesla scanner (MAGNE- TOM Trio Tim system, Siemens, Erlangen, Germany, 12 channel head coil) at Neurospin, CEA-Saclay, France. Imaging sequences included a high-resolution 3D T1- weighted volume using a magnetization-prepared rapid acquisition gradient-echo sequence [176 slices, repetition time (TR) $2300 \mathrm{msec}$, echo time (TE) $4.18 \mathrm{msec}$, field of view (FOV) $256 \mathrm{~mm}$, flip angle=9, voxel size $1 \times 1 \times 1 \mathrm{~mm} 3$ ], a 3D T2 FLAIR sequence [160 slices, TR 5,000 msec, TE 395msec, FOV $230 \mathrm{~mm}$, voxel size $0.9 \times$ $0.9 \times 1 \mathrm{~mm} 3$. MRI images were all inspected for abnormalities and inconsistencies by senior paediatric neuroradiologists and physical and rehabilitation medicine practitioners. For the NAIS patients, lesions were manually identified and outlined by two paediatric physical and rehabilitation medicine practitioners (MD and SG, co-authors). This was done on a slice by slice basis on the individual 3D T1 images in order to create a binary lesion mask using the MRIcron software (http://www.mccauslandcenter.sc.edu/mricro) (Rorden, Karnath, \& Bonilha, 2007). For an optimum result, the co-registered 3D FLAIR images were used as a visual aid for accurate lesion delineation where the hyper-intense areas on FLAIR were defined as part of the lesion (Dinomais et al., 2015). Afterwards, obtained lesion masks were double 
checked by each practitioner and were spatially normalized. For in depth details about lesion delineation and localization please refer to (Dinomais et al., 2015).

All T1 images were processed using the FreeSurfer suite, version 6.0.0 (https://surfer.nmr.mgh.harvard.edu/), on a single DELL workstation running ubuntu 16.04 LTS (Intel R Core TM i7-7820HQ CPU @ 2.9GHz × 8). The FreeSurfer processing pipeline carries out an automated cortical surface reconstruction process that includes various steps (for detailed description of the different surface-based pipeline please refer to (Dale, Fischl, \& Sereno, 1999; Fischl et al., 1999, 2000, 2001, 2002, 2004). Concisely, these steps contain motion correction, non-uniform intensity normalization, automated Talairach transformation, skull stripping, subcortical and cortical matter segmentation, tessellation and depiction of grey/white/pial boundaries (Dale, Fischl, \& Sereno, 1999; Fischl et al., 1999, 2001). In order to improve the segmentation and therefore the computing of the different parameters, we used the $\mathrm{T} 2$-weighted images as auxiliary to the $\mathrm{T} 1$ images. This additional contrast in the $\mathrm{T} 2$ images allows more accurate pial surfaces definitions especially in the presence of lesions. After the creation of the final surfaces, deformation operations are applied in order to inflate and register the surface to a spherical atlas (Fischl et al., 2002). Then, parcellation of the cerebral cortex is performed and different statistics are computed (Fischl et al., 2004). In this work, we used the Destrieux atlas (Fischl et al., 2004) for the parcellation of the cortex into gyral regions.

Images of each participant (patients and controls) were inspected and visually checked after the segmentation process by a rehabilitation medicine practitioner (MD, last author). Four patients of the 38 were excluded from the study due to irrevocable errors in the segmentation results around and near the lesion despite attempts to manually edit and improve the results. Total Intracranial Volume (TIV) for all participants was estimated by FreeSurfer as part of the statistics.

\section{Cortical thickness, surface area and cortical volume}

Cortical thickness is computed at each vertex as the shortest distance between the pial surface and the white/grey boundary (Fischl \& Dale, 2000). The obtained cortical thickness values are not restricted to the voxel resolution of the initial data. Accordingly, these maps have a submillimetre accuracy of around 150000 vertices for each surface mesh of the cerebral hemispheres which means a comparison at a sub-millimetre scale between the groups. The algorithm used by FreeSurfer for the computing of cortical thickness was validated and proven 
to be reliable by various studies (Kuperberg et al., 2003; Kelly et al., 2013; Besteher, Gaser, Spalthoff, \& Nenadic, 2017).

Surface area is estimated at the pial level. It is computed for each vertex of the grey matter by averaging the areas of the tessellation triangles in contact with that vertex. The cortical volume calculated by FreeSurfer is obtained at each vertex, by surface-based calculations in order to obtain better accuracy. All the measures were estimated in the native space.

\section{Local Gyrification Index}

In this work, cortical gyrification was computed using a surface-based approach that is available as auxiliary measure in FreeSurfer (Schaer et al., 2008). This quantification of cortical folding is called Local Gyrification Index (LGI). It is a 3-D adaptation of the 2-D Gyrification index (GI) proposed by Zilles, Armstrong, Schleicher, \& Kretschmann (1988). They computed the GI, at the coronal sections level, as the complex cortical surface proportion of the total brain perimeter (Schaer et al., 2008). The LGI developed by Schaer et al. (2008) overcomes the limitation of the 2-D GI by taking into account the 3-D character of the cortical exterior compared to the GI that can suffer from inaccuracies due to buried sulci and slice orientation, not to mention the problems of manual tracing used in the 2-D approach. The LGI has been recently used in different studies in order to evaluate the gyrification abnormalities (Kelly et al., 2013), folding deficit (Hyatt, Haney-Caron, \& Stevens, 2012) or to quantify regional differences in gyrification (Palaniyappan, Mallikarjun, Joseph, White, \& Liddle, 2011). This LGI is a new 3-D parameter that aims to compute and compare local cortical gyrification at thousands of points throughout the entire hemisphere using 3-D cortical reconstruction (Schaer et al., 2008). It is the vertex wise ratio of the folded pial surface area, computed over a circular region of interest with $25 \mathrm{~mm}$ radius, to an outer surface. This outer surface area is defined as an outer hull layer that closely wraps around the pial surface and thus envelops the outer cortex perimeter. The obtained LGI maps describe the portion of cortex concealed in the sulcal folds of the brain at each pial surface vetted and therefore it is a direct measure of the cortical folding. For in depth description of the LGI computation algorithm please refer to (Schaer et al., 2008).

\section{Lesion Masks}

Total lesion maps for LLP and RLP were computed as the sum of the normalized binary individual masks for each group separately (for detail of lesion masking, see (Dinomais et al., 2015)). Thus, we obtained a LH and RH mask map for the LLP and RLP groups respectively 
(see Figure 1). These maps were then transformed into surface maps using a FreeSurfer function that assigns values from the volume to each surface vertex. Afterwards, we applied a threshold of $n>4$ and $n>3$ for LLP and RLP groups respectively (Lo, Gitelman, Levy, Hulvershorn, \& Parrish, 2010; Geva, S., Baron, Jones, Price, \& Warburton, 2012) which is equivalent to $n>$ $20 \%$ of the total participants. Finally, these maps were binarized in order to obtain the final masks for LLP and RLP. The block diagram of the lesion masks computing is detailed in Figure 1. The lesion masks represent the portion of the brain where lesions occurred for the previously described patients. Appropriately, it was important to compute these masks in order to study the effect of NAIS outside these regions by excluding them from the statistical tests.

\section{Statistical Analysis}

For all four parameters (cortical thickness, surface area, cortical volume and LGI), statistical analysis was carried using the general linear modelling built-in tool in FreeSurfer. Between group surface differences were run for each hemisphere separately using two-sample t-test models. First, all measurement values were resampled and mapped to the fsaverage subject provided by FreeSurfer and smoothed by an $8 \mathrm{~mm}$ full-width-at-half-maximal Gaussian kernel. Then, vertex-wise comparisons between HC and each of the patient groups (LLP and RLP) are performed for each parameter and hemisphere at a time. These analyses were controlled for sex and handedness considering the account these parameters can have on the obtained clusters (Sowell et al., 2006; Kong et al., 2018). No significant group differences were detected between controls (HC) and patients (LLP and RLP) in age $(\mathrm{p}=0.543)$ or TIV $(\mathrm{p}=0.127)$ (Table 1). As a result, they were not included as covariates. We also have to mention that the final lesion masks for LLP and RLP groups (please refer to section MRI Acquisition and Processing) were added as parameter to the statistical analysis in order to exclude the lesioned area from the test. This ensures that the obtained clusters are external to the corresponding lesion mask in each case. Finally, between-group differences were corrected for multiple comparisons using a cluster wise correction using two-tailed Monte Carlo z-field simulation with $\mathrm{p}<0.05$. This approach of correction offered by FreeSurfer is similar to Gaussian Random Fields (GRF) though it uses a simulation instead of analytic equations for the corrected voxel-wise and cluster wise $p$-values estimation (Hagler Jr, Saygin, \& Sereno, 2006).

\section{Results}


Figures 2 and 3 show sets of significant clusters for cortical thickness, surface area, cortical volume and LGI representing the following comparisons: HC versus LLP (Fig. 2) and HC versus RLP (Fig. 3). These results of vertex-by-vertex comparisons were all corrected for sex and handedness. Multiple comparisons were Monte Carlo corrected. The lesion regions delineated by the total LLP and RLP masks, previously described in detail (section Lesion Masks), were excluded from the statistical analysis in order to study the lesion impact on the brain accurately. These masks are displayed in Figures 2 and 3 (green colour). The details of the significant clusters are presented in Tables 2 and 3 for the two comparisons previously mentioned.

\section{HC Versus LLP}

The cortical thickness analysis for the HC versus LLP groups exhibits a significantly thinner cortex for the LLP subjects (Fig. 2A). These significantly inferior values of cortical thickness were observed only for the lesioned hemisphere (LH). The contralesional hemisphere (RH) in this case did not show any significant thinning compared to the controls. By observing the obtained clusters in the LH in Fig. 2A, multiple small clusters were localized around the lesion area (close to the lesion mask). Main clusters that survived whole brain correction were located, based on the Destrieux parcellation atlas (Fischl et al., 2004), in the postcentral sulcus, superior segment of the circular sulcus of the insula and the inferior part of the precentral sulcus (Table 2).

For the surface area analysis, we obtained four major clusters (see Fig. 2B, Table 2) in the LH part of the brain. These clusters indicate a significantly reduced average surface area at the transverse temporal sulcus, the inferior segment of the circular sulcus of the insula, the precentral gyrus and the intraparietal sulcus and transverse parietal sulci for the LLP subjects in comparison with the healthy subjects (HC). These brain regions with reduced surface area values are encircling the total lesion mask. For the $\mathrm{RH}$ part of the brain, the surface area investigation determined one cluster where the surface area values of the LLP subjects were significantly higher than the HC group ones. These higher values of surface area of the contralesional hemisphere of LLP subjects were located, according to the Destrieux atlas, at the occipital pole. No other significant clusters survived whole brain cluster correction in the RH. Similar to the surface area analysis, cortical volume evaluation between LLP and HC groups revealed inferior cortical volume of the LLP subjects as to the HC group in the lesioned hemisphere (LH). This smaller cortical volume is located in nine different clusters (Fig. 2C, 
Table 2). Main clusters that survived Monte Carlo null-z simulation correction are located at the inferior segment of the circular sulcus of the insula, the transverse temporal sulcus, the angular gyrus and the inferior part of the precentral sulcus. Smaller but significant clusters were found at the lingual and temporal gyrus areas of the brain. For the RH section of the brain, similarly to the surface area analysis, we identified one cluster that indicated a significantly higher cortical volume for the LLP subjects compared to the healthy subjects (Fig. 2C, Table 2). Based on the Destrieux atlas annotation, this cluster peak coordinate fell within the superior occipital gyrus.

Between group comparison for LLP and HC groups of LGI revealed two significant clusters in the LH with reduced gyrification in the LLP group compared to the HC groups and three significant clusters in the RH with more important gyrification in the LH for the same patients versus healthy subjects (Fig. 2D, Table 2). For the lesioned hemisphere (LH), automated annotation of the group structural data identified the first and biggest cluster as part of the subcentral gyrus and sulci regions of the brain. The second cluster that survived the Monte Carlo correction $(\mathrm{P}<0.05)$ was located in the Anterior occipital sulcus and preoccipital notch. Regarding the RH region of the brain, the clusters with more important gyrification lied in the superior occipital gyrus, superior frontal gyrus and superior part of the precentral sulcus (Fig. 2D, Table 2). Table 2 summarizes the obtained cluster statistics for both $\mathrm{LH}$ and $\mathrm{RH}$ in the case of LLP versus HC.

\section{HC Versus RLP}

For the cortical thickness analysis, there were only small insubstantial clusters remaining in the RH after Monte Carlo null-z simulation correction and lesion masking by employing the RLP lesion mask (Table3). One of these small clusters is located in the postcentral gyrus and was reduced in size after adding the RLP lesion mask. In the contralesional hemisphere (LH), none of the clusters survived the whole brain cluster correction.

Surface area examination revealed inferior average surface area values for the RLP subjects with respect to the $\mathrm{HC}$ group in the RH of the brain (Fig. 3B and Table 3). Significantly lower surface area values were mainly observed in five clusters positioned at the posterior ramus of the lateral sulcus, angular gyrus, middle frontal sulcus, middle occipital gyrus and middle temporal gyrus (Table 3). Smaller but significant clusters were found in the suborbital sulcus, supramarginal gyrus and postcentral gyrus. For the healthy hemisphere (LH), no clusters were found after multiple comparison correction. 
After analysis of the cortical volume, we observed complementary results to the surface area study. We found no significant difference after Monte Carlo correction between RLP and HC groups for the LH. However, for the lesioned hemisphere (RH) we identified seven more or less small clusters indicating inferior cortical volume for the RLP participants compared to the HC subjects (Fig. 3C, Table 3). The biggest identified cluster was located, according to the Destrieux atlas annotation, in the posterior ramus of the lateral sulcus. The other clusters were smaller in size and they were sitting in the angular gyrus, postcentral gyrus, anterior and middle occipital sulcus, inferior temporal gyrus and subcentral gyrus and sulci.

In the case of the LGI for the RLP versus HC groups, no significant differences in gyrification were detected for the RH. Nonetheless, for the healthy hemisphere (LH), group comparisons revealed higher gyrification for the RLP participants in comparison with healthy subjects. Two clusters survived the Monte Carlo null-z simulation correction $(\mathrm{p}<0.05)$. These clusters were located in the Middle occipital gyrus and Precuneus (see Table 3).

\section{Discussion}

In this work, a surface-based analysis approach was used in order to study the structural brain abnormalities in seven-year-old children that sustained a NAIS. Taking into account the asymmetry of the brain (Kong et al., 2018), structural changes were compared for the LLP and RLP groups separately. This allowed us to study the influence of the lesion lateralization on the obtained structural changes of the brain.

For the LLP group, we obtained lower cortical thickness, surface area, volume and LGI in the LH near the infarct site as presented (Fig. 2). Affected areas of the LH were found in the frontal, temporal and parietal lobes. For the surface area and cortical volume, principal clusters were found in the same regions of the brain at the inferior segment of the circular sulcus of the insula and transverse temporal sulcus (Table 2). Since cortical volume is considered as the product of cortical thickness and surface area and is affected by both measures in many studies (Winkler et al., 2010; Gerrits et al., 2016; Kong et al. 2018), it was expected that cortical volume and surface area results will be related. However, cortical thickness was proven to be independent from the surface area and volume. Therefore, the obtained clusters seem coherent especially since the clusters representing lower cortical thickness seem to be placed near and even at the edge of those of the surface area and cortical volume.

The degeneration in the cortical matter was anticipated since they fall into the MCA vascular territory (Kandel et al., 2000). This indicates that damage do not only affect the lesion territory 
but also sites distant from the injury based on the axotomy phenomenon that causes chain reactions including Wallerian degeneration and destruction of glial cells (Kandel et al., 2000). Moreover, the clusters obtained in the LH of the LLP group seem to be associated with the language area. This can point out a correlation with language and speech outcomes. Especially since the language area is located in the LH.

One of the main findings in this study was obtained when comparing the contralesional hemisphere (RH) of LLP subjects to the RH of the HC group. We observed greater surface area and as follows cortical volume of the LLP group in the occipital pole and superior occipital gyrus respectively (Fig. 2). Although cortical thickness results did not reveal any significant clusters after Monte Carlo correction, surface area and cortical volume variations are normally driven by cortical thickness alteration (Rimol et al., 2012). On that account, we found that we did have a significantly superior cortical thickness in the middle occipital gyrus (uncorrected $p$ $<0.05$ ) without surviving correction for multiple comparison (supplementary Fig.1). This provides evidence that in the case of NAIS with lesion in the LH, the RH part of the brain does not stay intact. This alteration of the contralesional hemisphere $(\mathrm{RH})$ in the case of the LLP group is unexpected and it can be attributed to a number of reasons. The higher cortical surface, volume and LGI can be explained as a form of adjustment or compensation to the lower grey matter in the lesioned hemisphere. It can also be interpreted as a mechanical effect of the lesion on the growth of the opposite hemisphere. More precisely, it can mean that as a response to the lesion, the contralesional hemisphere can reflect an improved maturation in certain clusters (Remer et al., 2017).

Gyrification analysis for the LLP group was consistent with reduced surface area and cortical volume where reduced cortical folding. The overlapping of the obtained LGI clusters with those of cortical volume and surface area is also found in the RH where we discovered more gyrification for LLP subjects relative to HC in the superior occipital gyrus. Two other clusters fell in the superior frontal gyrus and superior part of the precentral sulcus respectively. In the case of RLP group in comparison with the healthy subjects, we observed reduced surface area and cortical volume in the posterior ramus of the lateral sulcus, angular gyrus, postcentral gyrus and middle occipital gyrus of the lesioned hemisphere as well as other regions (Table 3). For the cortical thickness we found two very small clusters, the first representing less cortical thickness in the postcentral gyrus and the second representing extra cortical thickness at the pericallosal sulcus. The second cluster was assumed to be irrelevant due to its size. These clusters differ from the ones obtained in the LLP versus HC case for the lesioned hemisphere. In this case, clusters were found scattered all over the brain lobes and were not concentrated 
near the lesion site like in the case of LLP and HC comparison clusters. Moreover, we found reduced surface area and cortical volume in the middle occipital gyrus for the RLP subjects in contrast to the increased grey matter observed for the LLP group in the RH. The thinning in the cortical matter at the presented regions of the brain can equally be explained by the Wallerian degeneration introduced in the LLP cases. In the case of the gyrification assessment in the RH of RLP, no significant differences were observed after multiple comparison correction. This may be explained by the fact that the individual normalized lesion maps in the RLP case were less overlapping than the LLP ones (Fig. 1).

Considering the group comparison between contralesional hemisphere of RLP group (RH) and the corresponding hemisphere of the HC group, no clusters have survived the Monte Carlo correction for the cortical thickness, surface area and cortical volume. Nonetheless, for the LGI two clusters, indicating higher gyrification for the RLP group, were obtained in the middle occipital gyrus and precuneus. Accordingly, even though we did not obtain the same transformation pattern as the one observed in the LLP case for the cortical thickness, surface area and cortical volume, local gyrification has detected a compensation type abnormality in different regions as the ones found for the LLP groups.

The interesting aspect found in the present findings is that the higher grey matter observed by surface area and cortical volume growth of occipital pole and gyrus regions in the healthy hemisphere is only observed for the LLP groups. This can be explained by different theories. One suggestion is that lesion lateralization have a decisive impact on the brain adaptation. This structural alteration is only observed in the contralesional hemisphere of the brain. Other theories may link the results variety between RLP group in comparison with the LLP group to the different lesion positions in the brain for the two groups with respect to the MCA territory (please refer to Fig. 1). Nevertheless, this last explanation does not justify the absence of variation for the surface area, cortical thickness and volume in the healthy hemisphere for the RLP case. Another analysis can consider the difference to be related to the moderate number of subjects per patient group ( $n=19$ for LLP and $n=15$ for RLP). However, $n=15$ is considered to be the minimal number of sample subjects in order to conduct reliable statistical analysis of this kind (Kong et al., 2018). Furthermore, in the case of uncorrected comparisons $(p<0.001)$ for both cases (LLP versus HC and RLP versus HC) we found similar results as the ones presented in this manuscript. This means that even in the case of uncorrected comparison, we did not observe higher cortical thickness, volume or surface area in the healthy hemisphere (LH) for the RLP group. Based on all of the above, the first theory suggesting that lesion lateralization plays a major role in the morphological abnormalities observed in children brains after NAIS, 
seems to be the most reasonable. This theory can be further explained by considering the brain asymmetry and particularly the right frontal and left occipital petalia impressions. These impressions cause swelling of these regions in comparison with the opposite hemisphere (Toga and Thompson, 2003).

Another angle to consider in this study is the LGI metric. It seems that this particular parameter conveys more prominent results than the other markers especially for the contralesional hemisphere variation study in both LLP and RLP cases. The gyrification index is linked to the cerebral function and form and can allow to better understand the structural configuration, complexity and variability of the brain (Schaer et al., 2008; White et al., 2010). Thus, the question to ask is whether the LGI results presented in this study for the contralesional hemisphere indicate that the gyrification index is more sensitive to the cortical morphology impacted by a mechanical growth effect to counterbalance the deterioration of the opposite hemisphere.

Further work is required in order to find the link between the obtained findings and the clinical and neurological characteristics of patients from both groups (LLP and RLP). This can be done by studying the correlation between clinical scores and the four parameters presented in this study (cortical thickness, surface area, cortical volume and LGI). In addition, neurological examination of patients related to visual processing can help support and approve the results presented in this paper especially for the suggested adaptation theory in the case of LLP subjects. This can also help us explain and link the more important cortical matter in the occipital regions of the RH for the LLP to advanced visual tasks and compare these findings with the corresponding ones for the RLP group.

In this study we presented an original morphometric surface-based analysis of the human brain for seven-year-old children that sustained a NAIS. There is, however, some limitations in our approach that we need to point out. One of the main difficulties we had is related to the segmentation process in the case of the lesioned brains (LLP and RLP) which was more challenging for the subjects with larger lesions. In these cases, the segmentation was difficult around and near the lesion site even by manual correction. However, this did not affect the segmentation for the healthy hemispheres. Therefore, the findings obtained in the case of the healthy hemisphere studies (RH for LLP and LH for RLP) were not affected by this. We also have to mention that the lesion delineation was performed using an expert consensus approach (Dinomais et al., 2015), which can introduce a certain subjectivity to the results. 


\section{Conclusion}

\section{Funding}

The research was supported by the University hospital of Angers (eudract number 2010A00976-33), the University hospital of Saint-étienne (eudract number 2010-A00329-30), and the Fondation de l'Avenir (ET0-571). M Al Harrach, A Bohi, and X Wang were supported by grants obtained from the Fondation pour la Recherche Médicale (FRM-DIC20161236453). Sponsors of the study had no role in the study design data collection, data analysis, data interpretation, writing of the report, or decision to submit for publication.

\section{Conflict of Interest}

None declared.

\section{References}

Besteher, B., Gaser, C., Spalthoff, R., \& Nenadic, I. (2017). Associations between urban upbringing and cortical thickness and gyrification. Journal of psychiatric research, 95, $114-120$.

https://doi.org/10.1016/j.jpsychires.2017.08.012

Boardman, J. P., Ganesan, V., Rutherford, M. A., Saunders, D. E., Mercuri, E., \& Cowan, F. (2005). Magnetic resonance image correlates of hemiparesis after neonatal and childhood middle cerebral artery stroke. Pediatrics, 115, 321-326.

https://doi.org/10.1542/peds.2004-0427

Chabrier, S., Peyric, E., Drutel, L., Deron, J., Kossorotoff, M., Dinomais, M., Lazaro, L., Lefranc, J., Thebault, G., Dray, G., Fluss, J., Renaud, C., Nguyen The Tich, S., \& Accident Vasculaire Cerebral du nouveau-ne (AVCnn; [Neonatal Stroke]) Study Group (2016). Multimodal Outcome at 7 Years of Age after Neonatal Arterial Ischemic Stroke. The Journal of Pediatrics, 172, 156-161.e3.

https://doi.org/10.1016/j.jpeds.2016.01.069

Dale, A. M., Fischl, B., \& Sereno, M. I. (1999). Cortical surface-based analysis: I. segmentation and surface reconstruction. Neuroimage, 9, 179-194.

https://doi.org/10.1006/nimg.1998.0395 
Darmency-Stamboul, V., Cordier, A., \& Chabrier, S. (2017). Neonatal arterial ischemic stroke in term or near-term newborns: prevalence and risk factors. Archives de pediatrie: organe officiel de la Societe francaise de pediatrie, 24, 9S3-9S11.

https://doi.org/10.1016/S0929-693X(17)30325-1

Dinomais, M., Hertz-Pannier, L., Groeschel, S., Chabrier, S., Delion, M., Husson, B., Kossorotoff, M., Renaud, C., Nguyen The Tich, S., \& AVCnn Study Group (2015). Long term motor function after neonatal stroke: Lesion localization above all. Human Brain Mapping, 36, 4793-4807.

https://doi.org/10.1002/hbm.22950

Dinomais, M., Hertz-Pannier, L., Groeschel, S., Delion, M., Husson, B., Kossorotoff, M., Renaud, C., Chabrier, S., The Tich, S. N., \& AVCnn Study Group. Does Contralesional Hand Function After Neonatal Stroke Only Depend on Lesion Characteristics? Stroke, 47, $1647-1650$.

https://doi.org/10.1161/STROKEAHA.116.013545

Domi, T., deveber, G., Shroff, M., Kouzmitcheva, E., MacGregor, D. L., \& Kirton, A. (2009). Corticospinal tract pre-wallerian degeneration: a novel outcome predictor for pediatric stroke on acute mri. Stroke, 40, 780-787.

https://doi.org/10.1161/STROKEAHA.108.529958

Fiori, S. \& Guzzetta, A. (2015). Plasticity following early-life brain injury: insights from quantitative mri. In Seminars in perinatology, 39, 141-146. Elsevier.

https://doi.org/10.1053/j.semperi.2015.01.007

Fischl, B., Salat, D. H., Busa, E., Albert, M., Dieterich, M., Haselgrove, C., Van Der Kouwe, A., Killiany, R., Kennedy, D., Klaveness, S., et al. (2002). Whole brain segmentation: automated labeling of neuroanatomical structures in the human brain. Neuron, 33, 341-355. https://doi.org/10.1016/S0896-6273(02)00569-X

Fischl, B., Van Der Kouwe, A., Destrieux, C., Halgren, E., Segonne, F., Salat, D. H., Busa, E., Seidman, L. J., Goldstein, J., Kennedy, D., et al. (2004). Automatically parcellating the human cerebral cortex. Cerebral cortex, 14, 11-22.

https://doi.org/10.1093/cercor/bhg087

Gauthier, L. V., Taub, E., Mark, V. W., Barghi, A., \& Uswatte, G. (2012). Atrophy of spared gray matter tissue predicts poorer motor recovery and rehabilitation response in chronic stroke. Stroke, 43, 453-457.

https://doi.org/10.1161/STROKEAHA.111.633255 
Gerrits, N. J., van Loenhoud, A. C., van den Berg, S. F., Berendse, H. W., Foncke, E. M., Klein, M., Stoffers, D., van der Werf, Y. D., \& van den Heuvel, O. A. (2016). Cortical thickness, surface area and subcortical volume differentially contribute to cognitive heterogeneity in parkinsons disease. PloS one, 11, e0148852.

https://doi.org/10.1371/journal.pone.0148852

Geva, S., Baron, J.-C., Jones, P. S., Price, C. J., \& Warburton, E. A. (2012). A comparison of vlsm and vbm in a cohort of patients with post-stroke aphasia. NeuroImage: Clinical, 1, 3747.

https://doi.org/10.1016/j.nicl.2012.08.003

Grunt, S., Mazenauer, L., Buerki, S. E., Boltshauser, E., Mori, A. C., Datta, A. N., Fluss, J., Mercati, D., Keller, E., Maier, O., et al. (2015). Incidence and outcomes of symptomatic neonatal arterial ischemic stroke. Pediatrics, peds-2014.

https://doi.org/10.1542/peds.2014-1520

Hagler Jr,D. J., Saygin, A. P., \& Sereno, M. I. (2006). Smoothing and cluster thresholding for cortical surface-based group analysis of fmri data. Neuroimage, 33, 1093-1103.

https://doi.org/10.1016/j.neuroimage.2006.07.036

Husson, B., Hertz-Pannier, L., Renaud, C., Allard, D., Presles, E., Landrieu, P., Chabrier, S., et al. (2010). Motor outcomes after neonatal arterial ischemic stroke related to early mri data in a prospective study. Pediatrics, peds-2009.

https://doi.org/10.1542/peds.2009-3611

Hyatt, C. J., Haney-Caron, E., \& Stevens, M. C. (2012). Cortical thickness and folding deficits in conduct- disordered adolescents. Biological Psychiatry, 72, 207-214.

https://linkinghub.elsevier.com/retrieve/pii/S0006322311011589

Kandel, E. R., Schwartz, J. H., Jessell, T. M., of Biochemistry, D., Jessell, M. B. T., Siegelbaum, S., \& Hudspeth, A. (2000). Principles of neural science (volume 4). McGrawhill New York.

Kelly, P. A., Viding, E., Wallace, G. L., Schaer, M., De Brito, S. A., Robustelli, B., \& McCrory, E. J. (2013). Cortical thickness, surface area, and gyrification abnormalities in children exposed to maltreatment: neural markers of vulnerability? Biological psychiatry, 74, 845852.

https://doi.org/10.1016/j.biopsych.2013.06.020

Kirton, A., Armstrong-Wells, J., Chang, T., Rivkin, M. J., Hernandez, M., Carpenter, J., Yager, J. Y., Lynch, J. K., Ferriero, D. M., Investigators, I. P. S. S., et al. (2011). Symptomatic 
neonatal arterial ischemic stroke: the international pediatric stroke study. Pediatrics, pages peds-2011.

https://doi.org/10.1542/peds.2011-1148

Kirton, A. (2013). Modeling developmental plasticity after perinatal stroke: defining central therapeutic targets in cerebral palsy. Pediatric neurology, 48, 81-94.

https://doi.org/10.1016/j.pediatrneurol.2012.08.001

Kirton, A. \& deVeber, G. (2013). Life after perinatal stroke. Stroke, 44, 3265-3271.

https://doi.org/10.1161/STROKEAHA.113.000739

Kong, X.-Z., Mathias, S. R., Guadalupe, T., Glahn, D. C., Franke, B., Crivello, F., TzourioMazoyer, N., Fisher, S. E., Thompson, P. M., Francks, C., et al. (2018). Mapping cortical brain asymmetry in 17,141 healthy individuals worldwide via the enigma consortium. Proceedings of the National Academy of Sciences, 115, E5154-E5163.

https://doi.org/10.1073/pnas.1718418115

Kuperberg, G. R., Broome, M. R., McGuire, P. K., David, A. S., Eddy, M., Ozawa, F., Goff, D., West, W. C., Williams, S. C., van der Kouwe, A. J., et al. (2003). Regionally localized thinning of the cerebral cortex in schizophrenia. Archives of general psychiatry, 60, 878888.

https://doi.org/10.1001/archpsyc.60.9.878

Laugesaar, R., Kolk, A., Tomberg, T., Metsvaht, T., Lintrop, M., Varendi, H., \& Talvik, T. (2007). Acutely and retrospectively diagnosed perinatal stroke: a population-based study. Stroke, 38, 2234-2240.

https://doi.org/10.1161/STROKEAHA.107.483743

Lo, R., Gitelman, D., Levy, R., Hulvershorn, J., \& Parrish, T. (2010). Identification of critical areas for motor function recovery in chronic stroke subjects using voxel-based lesion symptom mapping. Neuroimage, 49, 9-18.

https://doi.org/10.1016/j.neuroimage.2009.08.044

Mercuri, E., Barnett, A., Rutherford, M., Guzzetta, A., Haataja, L., Cioni, G., Cowan, F., \& Dubowitz, L. (2004). Neonatal cerebral infarction and neuromotor outcome at school age. Pediatrics, 113, 95-100.

Oldfield, R. C. (1971). The assessment and analysis of handedness: the edinburgh inventory. Neuropsychologia, 9, 97-113.

https://doi.org/10.1016/0028-3932(71)90067-4 
Palaniyappan, L., Mallikarjun, P., Joseph, V., White, T. P., \& Liddle, P. F. (2011). Folding of the prefrontal cortex in schizophrenia: regional differences in gyrification. Biological psychiatry, 69, 974-979.

https://doi.org/10.1016/j.biopsych.2010.12.012

Raju, T. N., Nelson, K. B., Ferriero, D., Lynch, J. K., et al. (2007). Ischemic perinatal stroke: summary of a workshop sponsored by the national institute of child health and human development and the national institute of neurological disorders and stroke. Pediatrics, 120, 609-616.

https://doi.org/10.1542/peds.2007-0336

Remer, J., Croteau-Chonka, E., Dean III, D. C., D’arpino, S., Dirks, H., Whiley, D., \& Deoni, S. C. (2017). Quantifying cortical development in typically developing toddlers and young children, 1-6 years of age. Neuroimage, 153, 246-261.

https://doi.org/10.1016/j.neuroimage.2017.04.010

Rimol, L. M., Nesvag, R., Hagler Jr, D. J., Bergmann, Ø., Fennema-Notestine, C., Hartberg, C. B., Haukvik, U. K., Lange, E., Pung, C. J., Server, A., et al. (2012). Cortical volume, surface area, and thickness in schizophrenia and bipolar disorder. Biological psychiatry, 71, 552560 .

https://doi.org/10.1016/j.biopsych.2011.11.026

Rorden, C., Karnath, H.-O., \& Bonilha, L. (2007). Improving lesion-symptom mapping. Journal of cognitive neuroscience, 19, 1081-1088.

https://doi.org/10.1162/jocn.2007.19.7.1081

Schaer, M., Cuadra, M. B., Tamarit, L., Lazeyras, F., Eliez, S., \& Thiran, J.-P. (2008). A surface-based approach to quantify local cortical gyrification. IEEE transactions on medical imaging, 27, 161-170.

https://doi.org/10.1109/TMI.2007.903576

Schultz, C. C., Wagner, G., Koch, K., Gaser, C., Roebel, M., Schachtzabel, C., Nenadic, I., Reichenbach, J. R., Sauer, H., \& Schlösser, R. G. (2013). The visual cortex in schizophrenia: alterations of gyrification rather than cortical thickness a combined cortical shape analysis. Brain Structure and Function, 218, 51-58.

https://doi.org/10.1007/s00429-011-0374-1

Sowell, E. R., Peterson, B. S., Kan, E., Woods, R. P., Yoshii, J., Bansal, R., Xu, D., Zhu, H., Thompson, P. M., \& Toga, A. W. (2006). Sex differences in cortical thickness mapped in 176 healthy individuals between 7 and 87 years of age. Cerebral cortex, 17, 1550-1560.

https://doi.org/10.1093/cercor/bhl066 
Staudt, M. (2010a). Brain plasticity following early life brain injury: insights from neuroimaging. In Seminars in perinatology, 34, 87-92.

https://doi.org/10.1053/j.semperi.2009.10.009

Staudt, M. (2010b). Reorganization after pre-and perinatal brain lesions. Journal of Anatomy, 217, 469-474.

https://doi.org/10.1111/j.1469-7580.2010.01262.x

Stephan-Otto, C., Nunez, C., Arca, G., Agut, T., \& García-Alix, A. (2017). Three-dimensional map of neonatal arterial ischemic stroke distribution from early multimodal brain imaging. Stroke, 48, 482-485.

https://doi.org/10.1161/STROKEAHA.116.014186

Van Der Aa, N. E., Northington, F. J., Stone, B. S., Groenendaal, F., Benders, M. J., Porro, G., Yoshida, S., Mori, S., De Vries, L. S., \& Zhang, J. (2013). Quantification of white matter injury following neonatal stroke with serial dti. Pediatric research, 73, 756.

https://doi.org/10.1038/pr.2013.45

White, T., Su, S., Schmidt, M., Kao, C.-Y., \& Sapiro, G. (2010). The development of gyrification in childhood and adolescence. Brain and cognition, 72, 36-45.

https://doi.org/10.1016/j.bandc.2009.10.009

Winkler, A. M., Kochunov, P., Blangero, J., Almasy, L., Zilles, K., Fox, P. T., Duggirala, R., \& Glahn, D. C. (2010). Cortical thickness or grey matter volume? the importance of selecting the phenotype for imaging genetics studies. Neuroimage, 53, 1135-1146.

https://doi.org/10.1016/j.neuroimage.2009.12.028

Zewdie, E., Damji, O., Ciechanski, P., Seeger, T., \& Kirton, A. (2017). Contralesional corticomotor neurophysiology in hemiparetic children with perinatal stroke: developmental plasticity and clinical function. Neurorehabilitation and neural repair, 31, 261-271.

https://doi.org/10.1177/1545968316680485

Zilles, K., Armstrong, E., Schleicher, A., \& Kretschmann, H.-J. (1988). The human pattern of gyrification in the cerebral cortex. Anatomy and embryology, 179, 173-179.

https://doi.org/10.1007/BF00304699 


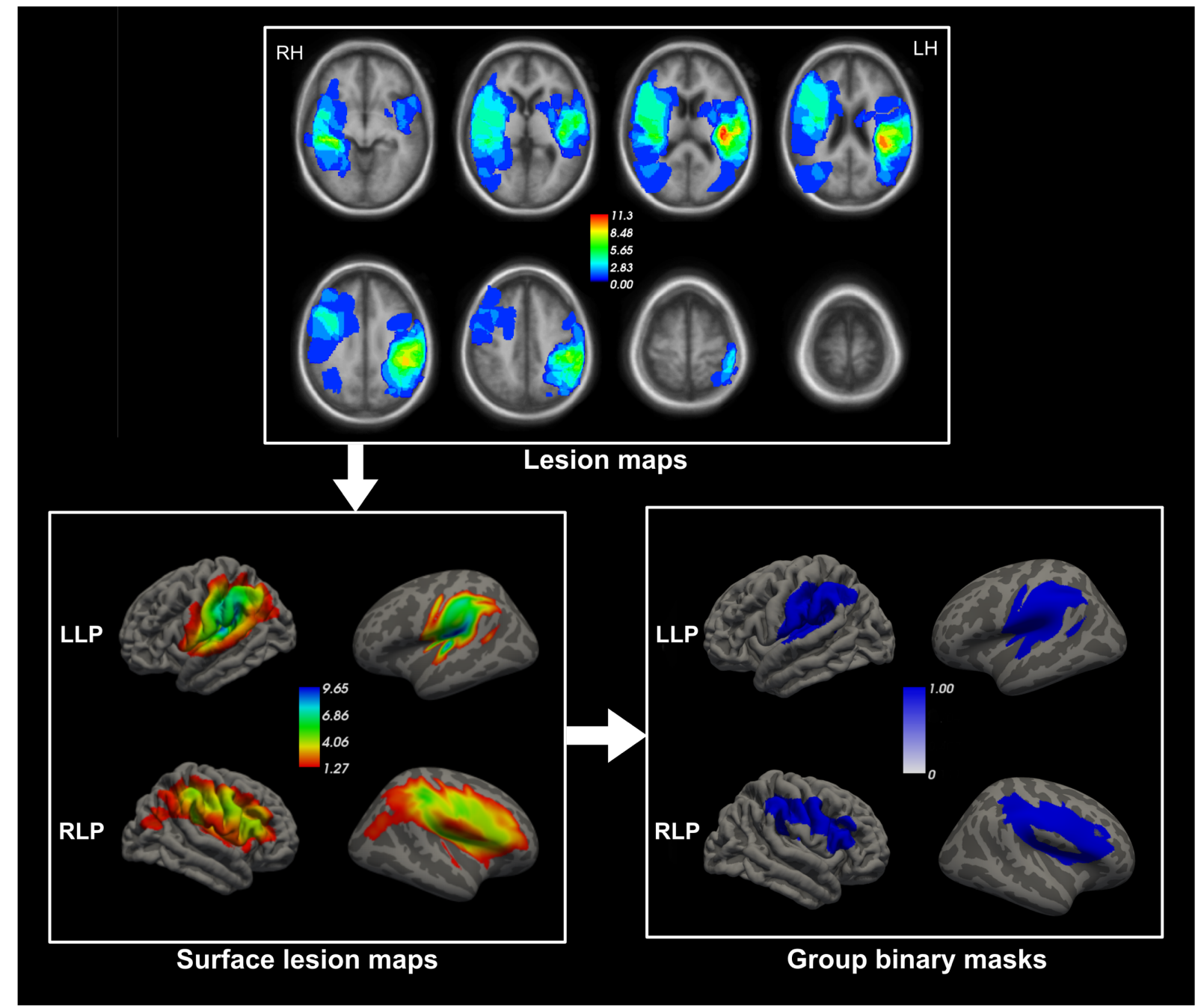

Figure 1: The pipeline used to obtain the surface lesion masks for LLP and RLP groups.

The group lesion masks for LLP (LH) and RLP (RH) were obtained by summing the normalized individual lesion masks. The second step consisted on transforming these maps from volumetric to surface space. Final step was the thresholding and binarization of the surface maps in order to obtain the final binary masks for the LLP and RLP groups. 


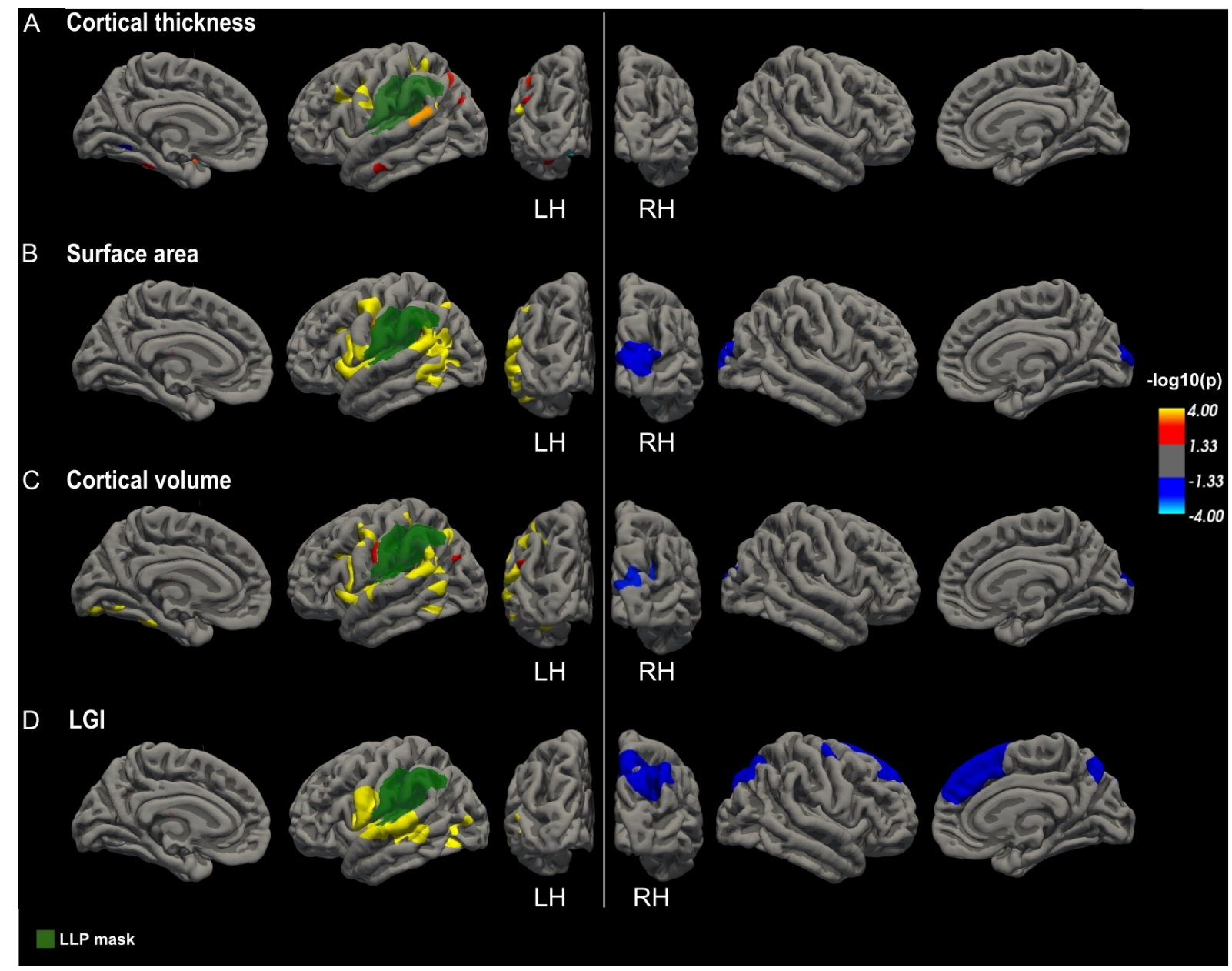

Figure 2: Between-group differences between HC and LLP $(p<0.05$ cluster level corrected) in cortical thickness (A), surface area (B), cortical volume (C) and LGI (D) projected onto the pial surface of the fsaverage in the medial, lateral and posterior view for the LH and the RH. Differences were computed separately for LH and RH. Clusters with red and yellow colours indicate brain regions where LLP have significantly lower cortical indexes values than the $\mathrm{HC}$ and clusters with blue colours indicate regions with increased values for LLP in comparison with HC. These clusters are defined in detail in Table 2. The final LLP mask is presented in green. 


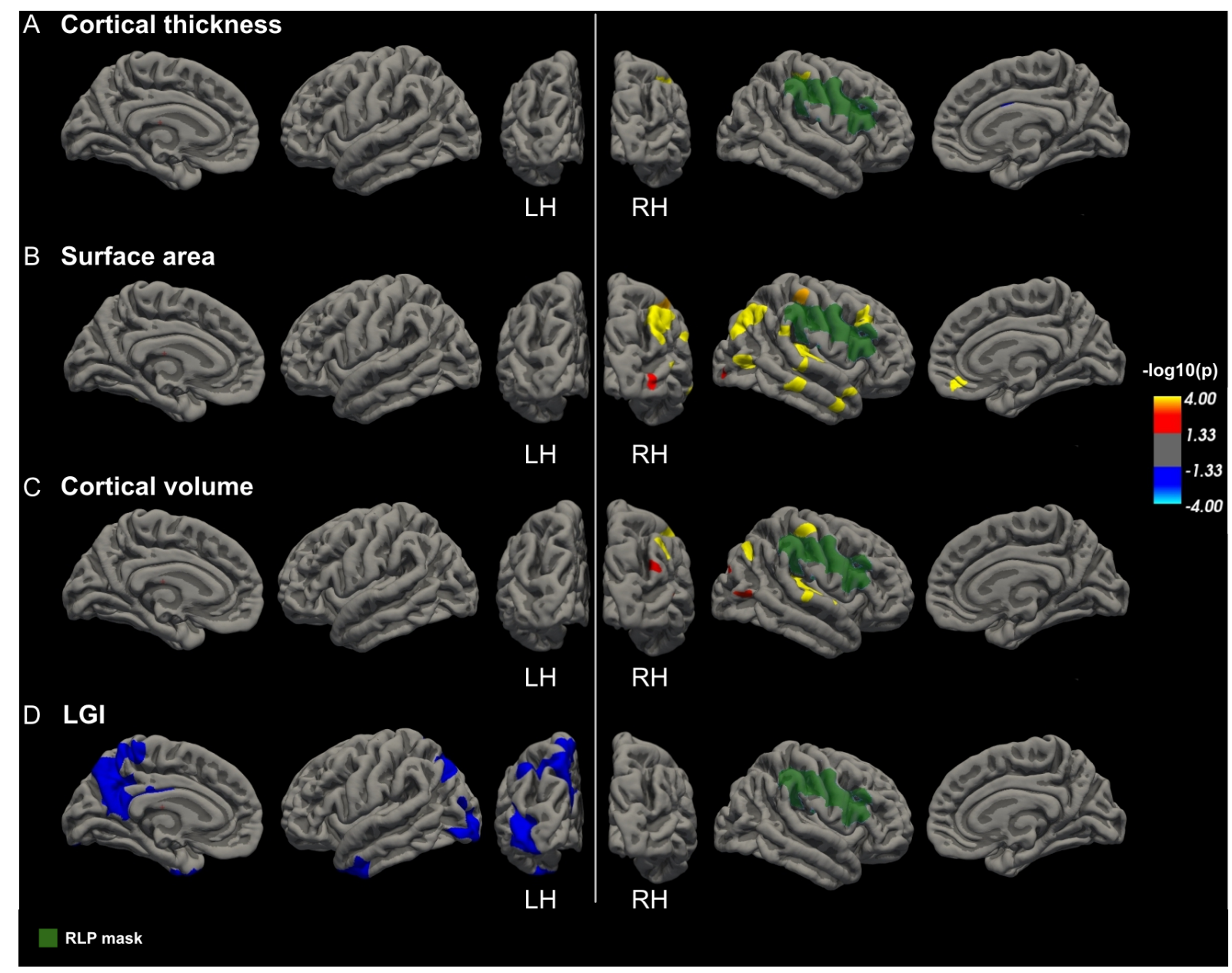

Figure 3: Between-group differences between HC and RLP (p $<0.05$ cluster level corrected) in cortical thickness (A), surface area (B), cortical volume (C) and LGI (D) projected onto the pial surface of the fsaverage in the medial, lateral and posterior view for the LH and the RH. Differences were computed separately for LH and RH. Clusters with red and yellow colours indicate brain regions where RLP have significantly lower cortical indexes values than the $\mathrm{HC}$ and clusters with blue colours indicate regions with increased values for RLP in comparison with HC. These clusters are defined in detail in Table 3. The final RLP mask is presented in green. 


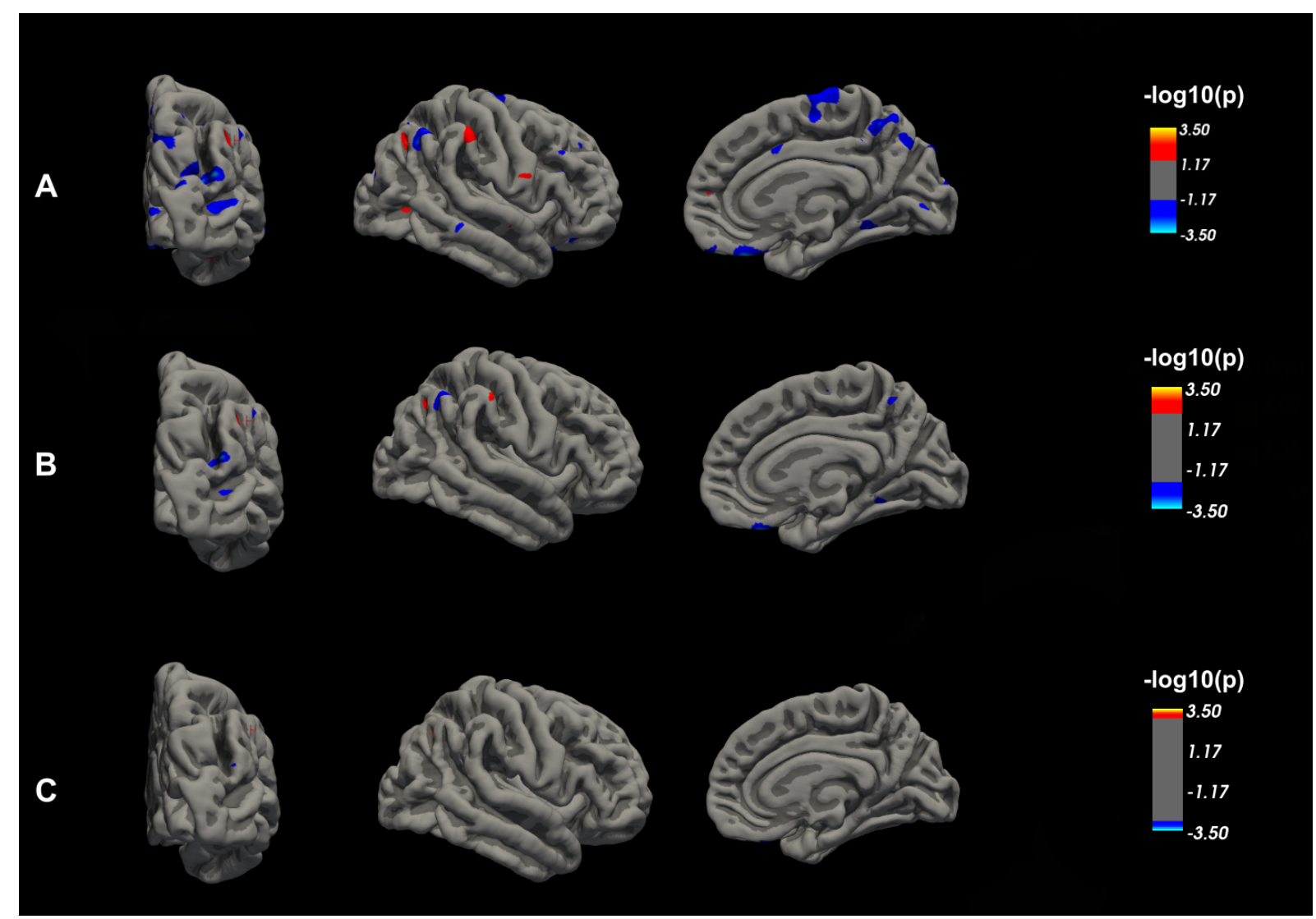

Supplementary Figure 1: Between-group differences between HC and LLP in cortical thickness, (A) p $<0.05$, (B) $\mathrm{p}<0.01$ and (C) $\mathbf{p}<0.001$ (Uncorrected). Clusters with red and yellow colours indicate brain regions where LLP have significantly lower cortical indexes values than the $\mathrm{HC}$ and clusters with blue colours indicate regions with increased values for LLP in comparison with HC. Clusters are projected onto the pial surface of the fsaverage in the medial, lateral and posterior view for the RH.

Table 1: General profile of the participants.

\begin{tabular}{|c|c|c|c|c|}
\hline & $\mathrm{HC}$ & LLP & & \\
\hline & $\begin{array}{l}\text { Mean }( \pm \text { std }) \text { or } n \\
(\%)\end{array}$ & $\begin{array}{l}\text { Mean }( \pm s t d) \text { or } n \\
(\%)\end{array}$ & $\begin{array}{l}\text { Mean }( \pm \text { std }) \text { or } n \\
(\%)\end{array}$ & value* \\
\hline & $\mathbf{n}=\mathbf{3 0}$ & $n=19$ & $n=15$ & \\
\hline $\begin{array}{l}\text { Age } \\
\text { (years) }\end{array}$ & $7.71( \pm 0.54)$ & $7.23( \pm 0.13)$ & $7.28 \pm 0.20)$ & 0.543 \\
\hline Gender & $\begin{array}{l}\text { Males: } 14(46.67 \%) \\
\text { Females: } 16(53.33 \%)\end{array}$ & $\begin{array}{l}\text { Males: } 10(52.63 \%) \\
\text { Females:9 }(47.37 \%)\end{array}$ & $\begin{array}{l}\text { Males: } 10(66.67 \%) \\
\text { Females: } 5(33.33 \%)\end{array}$ & $0.376^{\mathrm{a}}$ \\
\hline $\begin{array}{l}\text { Right- } \\
\text { handed }\end{array}$ & $27(90 \%)$ & $7(36.84 \%)$ & $14(93.33 \%)$ & $0.180^{\mathrm{a}}$ \\
\hline
\end{tabular}




\begin{tabular}{lllll}
\hline $\begin{array}{l}\text { Lesion } \\
\text { size }(\mathbf{m l})\end{array}$ & & $32.45( \pm 33.21)$ & $38.16( \pm 46.94)$ & 0.859 \\
\hline TIV & $1395.4( \pm 110.01)$ & $1307.0( \pm 157.71)$ & $1277.7( \pm 98.30)$ & 0.127
\end{tabular}

HC: Healthy Controls, LLP: Left Lesioned Patients, RLP: Right Lesioned Patients,

TIV: Total intracranial volume

* p-values are obtained by one-way Kruskal Wallis non-parametric ANOVA

${ }^{a}$ Chi squared test

Table 2: Significant clusters for the $\mathrm{LH}$ and $\mathrm{RH}$ resulting from the vertex wise comparison of cortical thickness, surface area, cortical volume and LGI between LLP and HC groups. LLP $<$ HC clusters are presented in white cells and LLP $>$ HC are presented in grey cells.

\begin{tabular}{|c|c|c|c|c|c|}
\hline LH/RH & $\begin{array}{c}\text { Cortical } \\
\text { index }\end{array}$ & Brain area & $\begin{array}{c}\text { Cluster } \\
\text { size } \\
\left(m m^{2}\right)\end{array}$ & $\begin{array}{c}\text { MNI } \\
\mathbf{x}, \mathbf{y}, \mathbf{z}\end{array}$ & p-value \\
\hline \multirow[t]{6}{*}{ RH } & $\begin{array}{l}\text { Cortical } \\
\text { thickness }\end{array}$ & 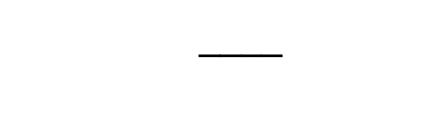 & 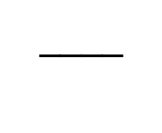 & 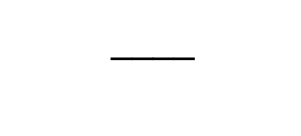 & - \\
\hline & Surface area & Occipital pole & 1538.71 & $9.4,-97.3,13.2$ & 0.0076 \\
\hline & $\begin{array}{l}\text { Cortical } \\
\text { volume }\end{array}$ & Superior occipital gyrus & 969.34 & $14.7,-94.0,12.4$ & 0.0015 \\
\hline & LGI & Superior occipital gyrus & 3065.30 & $26.1,-71.0,32.5$ & 0.0000 \\
\hline & & Superior frontal gyrus & 2703.80 & $7.4,24.0,57.1$ & 0.0000 \\
\hline & & $\begin{array}{l}\text { Superior part of the } \\
\text { precentral sulcus }\end{array}$ & 753.30 & $22.6,-6.8,48.7$ & 0.0000 \\
\hline LH & $\begin{array}{l}\text { Cortical } \\
\text { thickness }\end{array}$ & Postcentral sulcus & 490.93 & $\begin{array}{l}-31.1,-40.6 \\
44.4\end{array}$ & 0.0001 \\
\hline
\end{tabular}




\begin{tabular}{|c|c|c|c|c|}
\hline & $\begin{array}{l}\text { Superior segment of the } \\
\text { circular sulcus of the } \\
\text { insula }\end{array}$ & 470.17 & $-35.8,-9.7,16.9$ & 0.0001 \\
\hline & $\begin{array}{l}\text { Inferior part of the } \\
\text { precentral sulcus }\end{array}$ & 453.18 & $-42.2,-1.3,37.7$ & 0.0001 \\
\hline & Inferior frontal sulcus & 250.97 & $-37.4,14.4,23.0$ & 0.0001 \\
\hline & Angular gyrus & 145.55 & $\begin{array}{l}-52.7,-52.4 \\
18.5\end{array}$ & 0.0001 \\
\hline & Orbital sulci & 135.10 & $\begin{array}{c}-20.0,24.7,- \\
16.3\end{array}$ & 0.0001 \\
\hline & $\begin{array}{l}\text { Long insular gyrus and } \\
\text { central sulcus of the insula }\end{array}$ & 134.65 & $-36.7,1.5,-9.8$ & 0.0001 \\
\hline & $\begin{array}{l}\text { Lateral aspect of the } \\
\text { superior temporal gyrus }\end{array}$ & 124.22 & $61.4,-48.1,15.5$ & 0.0003 \\
\hline & $\begin{array}{l}\text { Intraparietal sulcus and } \\
\text { transverse parietal sulci }\end{array}$ & 106.94 & $\begin{array}{c}-29.8,-54.3 \\
35.9\end{array}$ & 0.0010 \\
\hline & $\begin{array}{l}\text { Planum polar of the } \\
\text { superior temporal gyrus }\end{array}$ & 105.27 & $-44.5,8.7,-24.1$ & 0.0011 \\
\hline \multirow[t]{4}{*}{ Surface area } & $\begin{array}{l}\text { Transverse temporal } \\
\text { sulcus }\end{array}$ & 3241.29 & $-44.6,-30.5,2.4$ & 0.0001 \\
\hline & $\begin{array}{l}\text { Inferior segment of the } \\
\text { circular sulcus of the } \\
\text { insula }\end{array}$ & 3009.35 & $-45.9,-20.5,-4.6$ & 0.0001 \\
\hline & Precentral gyrus & 858.32 & $-49.8,-8.4,41.3$ & 0.0001 \\
\hline & $\begin{array}{l}\text { Intraparietal sulcus and } \\
\text { transverse parietal sulci }\end{array}$ & 725.58 & $\begin{array}{c}-34.1,-58.4 \\
37.1\end{array}$ & 0.0001 \\
\hline
\end{tabular}




\begin{tabular}{|c|c|c|c|c|}
\hline & Subcentral gyrus and sulci & 117.20 & $-62.0,-8.9,26.9$ & 0.0005 \\
\hline & $\begin{array}{l}\text { Superior part of the } \\
\text { precentral sulcus }\end{array}$ & 93.23 & $\begin{array}{c}-26.7,-13.2 \\
53.9\end{array}$ & 0.0044 \\
\hline \multirow[t]{9}{*}{$\begin{array}{l}\text { Cortical } \\
\text { volume }\end{array}$} & $\begin{array}{l}\text { Inferior segment of the } \\
\text { circular sulcus of the } \\
\text { insula }\end{array}$ & 2610.56 & $-44.0,-23.7,-1.7$ & 0.0001 \\
\hline & $\begin{array}{l}\text { Transverse temporal } \\
\text { sulcus }\end{array}$ & 1058.67 & $-49.7,-30.4,3.4$ & 0.0001 \\
\hline & Angular gyrus & 890.85 & $\begin{array}{c}-41.3,-65.4 \\
39.6\end{array}$ & 0.0001 \\
\hline & $\begin{array}{l}\text { Inferior part of the } \\
\text { precentral sulcus }\end{array}$ & 507.72 & $-48.5,-1.9,40.0$ & 0.0001 \\
\hline & Lingual gyrus & 365.83 & $\begin{array}{c}-12.9,-82.2,- \\
12.6\end{array}$ & 0.0001 \\
\hline & Inferior temporal gyrus & 143.56 & $\begin{array}{c}-55.7,-53.8,- \\
13.0\end{array}$ & 0.0001 \\
\hline & Middle temporal gyrus & 129.62 & $-59.2,-58.2,2.3$ & 0.0001 \\
\hline & $\begin{array}{l}\text { Lateral occipito-temporal } \\
\text { gyrus }\end{array}$ & 128.40 & $\begin{array}{c}-32.5,-34.8,- \\
24.6\end{array}$ & 0.0001 \\
\hline & Subcentral gyrus and sulci & 107.54 & $-62.0,-8.9,26.9$ & 0.0010 \\
\hline \multirow[t]{2}{*}{ LGI } & Subcentral gyrus and sulci & 4447.37 & $-57.2,-0.1,10.7$ & 0.0001 \\
\hline & $\begin{array}{l}\text { Anterior occipital sulcus } \\
\text { and preoccipital notch }\end{array}$ & 619.36 & $-39.8,-68.1,-0.0$ & 0.0001 \\
\hline
\end{tabular}


Table 3: Significant clusters for the $\mathrm{LH}$ and $\mathrm{RH}$ resulting from the vertex wise comparison of cortical thickness, surface area, cortical volume and LGI between RLP and HC groups. RLP $<$ HC clusters are presented in white cells and RLP $>$ HC are presented in grey cells.

\begin{tabular}{|c|c|c|c|c|c|}
\hline LH/RH & $\begin{array}{l}\text { Cortical } \\
\text { index }\end{array}$ & Brain area & $\begin{array}{c}\text { Cluster } \\
\text { size } \\
\left(\mathrm{mm}^{2}\right)\end{array}$ & $\begin{array}{l}\text { MNI } \\
\mathbf{x}, \mathbf{y}, \mathbf{z}\end{array}$ & p-value \\
\hline \multirow[t]{18}{*}{$\begin{array}{l}\mathrm{RH} \\
\mathrm{RH}\end{array}$} & \multirow{2}{*}{$\begin{array}{l}\text { Cortical } \\
\text { thickness }\end{array}$} & Postcentral gyrus & 100.64 & $46.6,-24.8,51.3$ & 0.0015 \\
\hline & & Pericallosal sulcus & 71.81 & $3.6,2.0,28.7$ & 0.0394 \\
\hline & \multirow[t]{8}{*}{ Surface area } & $\begin{array}{l}\text { Posterior ramus of the } \\
\text { lateral sulcus }\end{array}$ & 1226.49 & $33.1,-28.7,19.9$ & 0.0001 \\
\hline & & Angular gyrus & 1079.26 & $43.9,-62.8,36.1$ & 0.0001 \\
\hline & & Middle frontal sulcus & 430.07 & $37.9,24.2,38.1$ & 0.0001 \\
\hline & & Middle occipital gyrus & 277.33 & $47.1,-74.8,4.6$ & 0.0001 \\
\hline & & Middle temporal gyrus & 265.06 & $56.8,-0.1,-28.8$ & 0.0001 \\
\hline & & Suborbital sulcus & 168.70 & $8.5,45.8,-14.8$ & 0.0001 \\
\hline & & Supramarginal gyrus & 141.42 & $60.4,-40.2,27.5$ & 0.0001 \\
\hline & & Postcentral gyrus & 122.57 & $43.6,-29.0,51.5$ & 0.0002 \\
\hline & \multirow{7}{*}{$\begin{array}{l}\text { Cortical } \\
\text { volume }\end{array}$} & $\begin{array}{l}\text { Posterior ramus of the } \\
\text { lateral sulcus }\end{array}$ & 775.09 & $33.0,-29.4,19.4$ & 0.0001 \\
\hline & & Angular gyrus & 192.83 & $40.9,-66.7,37.9$ & 0.0001 \\
\hline & & Postcentral gyrus & 166.21 & $47.8,-23.9,52.9$ & 0.0001 \\
\hline & & $\begin{array}{l}\text { Anterior occipital sulcus } \\
\text { and middle occipital gyrus }\end{array}$ & 103.97 & $44.0,-67.7,7.0$ & 0.0008 \\
\hline & & Middle occipital gyrus & 87.51 & $38.4,-81.8,26.5$ & 0.0078 \\
\hline & & Inferior temporal gyrus & 80.79 & $\begin{array}{ll}51.7, & -44.0, \\
19.5 & \end{array}$ & 0.0163 \\
\hline & & Subcentral gyrus and sulci & 75.60 & $63.2,-13.0,18.7$ & 0.0268 \\
\hline & LGI & & - & 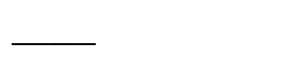 & - \\
\hline \multirow[t]{3}{*}{ LH } & $\begin{array}{l}\text { Cortical } \\
\text { thickness }\end{array}$ & 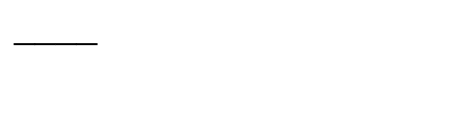 & & 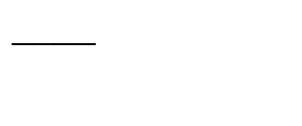 & 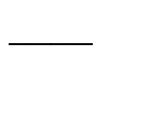 \\
\hline & Surface area & 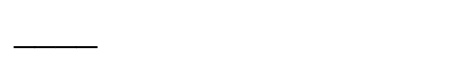 & - & 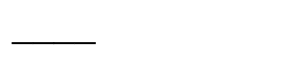 & - \\
\hline & $\begin{array}{l}\text { Cortical } \\
\text { volume }\end{array}$ & 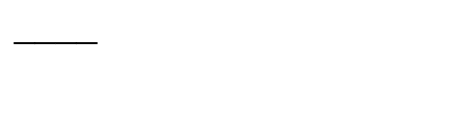 & & 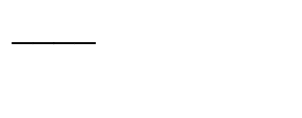 & - \\
\hline
\end{tabular}




\begin{tabular}{|l|l|l|l|l|l|}
\hline \multirow{2}{*}{ LGI } & Middle occipital gyrus & 2228.28 & $\begin{array}{l}-40.3,-81.8, \\
17.3\end{array}$ & 0.0001 \\
\cline { 3 - 5 } & & Precuneus & 1211.78 & $-6.4,-69.5,46.0$ & 0.0001 \\
\hline
\end{tabular}

